\title{
OXIDANTS, ANTIOXIDANTS AND CARDIOVASCULAR DISEASE
}

\author{
G. G. DUTHIE, K. W. J. WAHLE AND W. P. T. JAMES
}

Rowett Research Institute, Bucksburn, Aberdeen AB2 9SB

\section{CONTENTS}

INTRODUCTION . $\cdot$. . . . . . . . . . . . . 51

BIOLOGICAL IMPLICATIONS OF FREE RADICALS . . . . . . . 51

ANTIOXIDANT DEFENCE MECHANISMS . . . . . . . . . 53

EXPERIMENTAL EVIDENCE IMPLICATING FREE RADICALS IN
ATHEROSCLEROSIS

LIPID HYDROPEROXIDES . . . . . . . . . . . . . . 54

OXIDATION OF LOW-DENSITY LIPOPROTEINS . . . . . . . . . . . . 54

EPIDEMIOLOGICAL EVIDENCE FOR FREE RADICAL INVOLVEMENT

IN CARDIOVASCULAR DISEASE . . . . . . . . . . 56

ANTIOXIDANTS AND CARDIOVASCULAR DISEASE: INDIRECT
EVIDENCE

VITAMIN E $. \quad . \quad . \quad . \quad . \quad . \quad . \quad . \quad . \quad . \quad . \quad . \quad 57$

VITAMIN C $\mathrm{C}$.

SELENIUM . . . . . . . . . . . . . . . . . . 59

$\beta$-CAROTENE . . . . . . . . . . . . . . . . . . . . 59

CONCLUSION . . . . . . . . . . . . . . . . . . . . 60

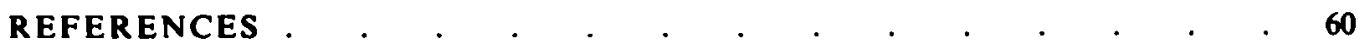

\section{INTRODUCTION}

Cardiovascular disease (CVD) remains the major cause of death in the United States and Western Europe and occlusion of the coronary arteries by the atheromatous plaque accounts for most of these deaths (Ross, 1986; Slattery \& Randall, 1988). Demographic differences in the incidence of CVD have been interpreted as implicating diet and cholesterol in the pathogenesis of the disease, but results of intervention trials to reduce serum cholesterol by dietary or pharmacological means are equivocal (Grundy, 1986; Reckless, 1987; Rifkind, 1987; Tyroler, 1987; James \& Ralph, 1988; McCormick \& Strabanek, 1988; Waterlow, 1988). Gey (1986) estimated that the major recognized risk factors for CVD, namely smoking, hypercholesterolaemia and hypertension, only account for $50-60 \%$ of the variance in the occurrence of CVD. Consequently, there is scope for the inclusion of other dependent and independent risk factors which may contribute to the apparent multifactorial nature of the disease. The purpose of the present article is to review recent evidence implicating reactive free radicals in the development of CVD.

\section{BIOLOGICAL IMPLICATIONS OF FREE RADICALS}

Free radicals are molecules or molecular fragments with an unpaired electron. The presence of the unpaired electron can convey considerable reactivity to the free radical which by 
hydrogen abstraction can damage a wide range of biological material, including DNA, nucleotide co-enzymes, proteins and lipids (Slater, 1984). Polyunsaturated fatty acids are particularly susceptible to free-radical-mediated peroxidation leading to disturbances in membrane structure and function (Slater et al. 1987). Free radicals have been implicated in the aetiology of many diseases, including tumour formation, toxic liver injury, neuromuscular disorders, arthritis, iron overload and gastrointestinal and liver disorders (Halliwell \& Grootveld, 1987). However, indications of free radical activity do not necessarily implicate free radicals as the prime cause of the disease. Tissue injury is liable to increase free radical reactions and consequently the presence of free radicals may arise as only a secondary consequence of the original disease state (Halliwell, 1987).

Endogenous production of free radicals occurs during normal aerobic metabolism. Activated oxygen intermediates are formed by stepwise reduction of $\mathrm{O}_{2}$ to water and by secondary reactions with protons and transition metals such as $\mathrm{Fe}$ and $\mathrm{Cu}$ (Byczkowski \& Gessner, 1988). The superoxide anion $\left(\mathrm{O}_{2}^{-}\right)$is produced by many cell redox systems including ischaemia-derived xanthine oxidase $(E C 1.1 .3 .22)$, aldehyde oxidase (EC 1.2.3.1) and membrane-associated NADPH oxidases (Fridovich, 1983). About $1-4 \%$ of the total $\mathrm{O}_{2}$ uptake by mitochondria may be used for $\mathrm{O}_{2}^{-}$production and about $20 \%$ of $\mathrm{O}_{2}^{-}$ produced intramitochondrially may be ejected into the cell (Forman \& Boveris, 1982). In addition, phagocytic cells, including macrophages and monocytes, increase their $\mathrm{O}_{2}$ uptake when stimulated and release large amounts of $\mathrm{O}_{2}^{-}$into the extracellular fluid through the action of NADPH oxidase (Klebanoff, 1982). Although $\mathrm{O}_{2}^{-}$is not particularly reactive, having a low second-order rate constant with biomolecules, it is capable of diffusing through relatively large distances through the cell where, in the presence of $\mathrm{Fe}$ and $\mathrm{Cu}$, a metal-catalysed Haber-Weiss reaction is thought to occur resulting in the formation of the highly reactive hydroxyl radical $\left(\mathrm{OH}^{\circ}\right)$ (Slater, 1984).

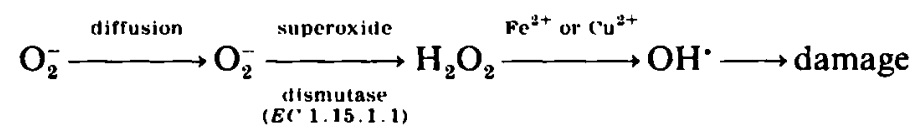

Although $\mathrm{Fe}$ and $\mathrm{Cu}$ are transported and stored in specific proteins which minimize their reaction with reduced $\mathrm{O}_{2}$ metabolites, under appropriate conditions such metal complexes are likely catalysts for in vivo $\mathrm{OH}^{*}$ production (Koster \& Slee, 1986). $\mathrm{OH}^{*}$ will react, in the immediate environment where it is produced, with most biological material (Slater, 1984) and these radicals are the major protagonists in the superoxide theory of $\mathrm{O}_{2}$ toxicity (Fridovich, 1983). This suggests that while $\mathrm{O}_{2}$ is essential for life, aerobic life forms persist despite their requirement for $\mathrm{O}_{2}$ (Bast, 1986). As well as being derived from $\mathrm{O}_{2}$ metabolism, potentially injurious free radicals are also present in pollutants, halogenated anaesthetics, and are generated by ionizing radiation (Halliwell \& Gutteridge, 1985). For instance, each puff of a cigarette contains $10^{14}$ free radicals in the gas phase and $10^{15}$ in the tar phase (Church \& Pryor, 1985), indicating that smokers are under a high and sustained free radical load which may cause tissue damage (Duthie et al. 1989).

Due to their short half-lives, relatively low concentrations and the ethical and logistical considerations in obtaining samples, the direct detection of free radicals in human tissue by electron-spin-resonance techniques is not usually feasible (Slater et al. 1987). Consequently, the presence of by-products of free radical-mediated damage to biomolecules in biological fluids is often used as an indirect measure of free radical stress. In particular, free radicalmediated peroxidation of polyunsaturated fatty acids yields a wide range of products (Slater, 1984). Many of these products, such as lipid hydroperoxides, conjugated dienes, malonaldehyde, fluorescent products, ethane and pentane are used to assess susceptibility to free radical activity. However, these indices can be non-specific and their production 


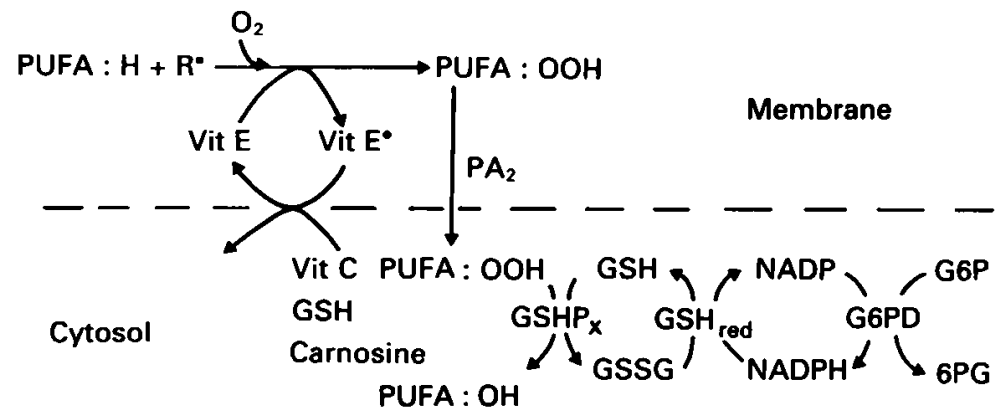

Fig. I. Some of the major antioxidant defence mechanisms within the cell. PUFA:H, polyunsaturated fatty acid; PUFA:OOH, fatty acid hydroperoxide; PUFA:OH, fatty acid hydroxide; GSH, reduced

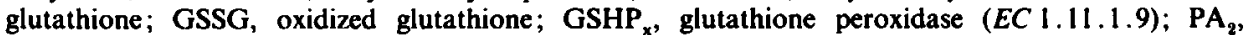
phospholipase $\mathrm{A}_{2}$ (EC 3.1.1.4); $\mathrm{GSH}_{\text {red }}$, glutathione reductase (EC 1.6.4.2); G6PD, glucose-6phosphate dehydrogenase (EC 1.1.1.49); 6PG, 6-phosphogluconoate; R', free radical.

does not necessarily relate directly to lipid peroxidation (Halliwell \& Gutteridge, 1985). For example, conjugated dienes may arise from dietary sources unrelated to free radicalmediated lipid peroxidation (Iversen et al. 1985) and the frequently used thiobarbituric acid test for malonaldehyde can react with other substances (Wade \& van Rij, 1988). Expired ethane and pentane, measures of lipid peroxidation of $\omega-3$ and $\omega-6$ fatty acids in vivo, may also arise through processes not related to free radical-mediated tissue damage, such as production by intestinal organisms and flushing from adipose tissue, and pentane may be metabolized by the liver before its detection in the expired breath (Duthie et al. 1987). As yet, no ideal method exists to assess free radical activity in humans, and results need to be interpreted with caution. New methods involving detection of by-products of free radical oxidation of uric acid and DNA in body fluids may offer alternative and more specific assessment of oxidant stress (Halliwell \& Grootveld, 1987).

\section{ANTIOXIDANT DEFENCE MECHANISMS}

Living organisms possess a range of mechanisms to protect themselves from the potentially injurious effects of free radicals. Vitamin $\mathrm{E}$ is the major lipid-soluble antioxidant breaking the chain of lipid peroxidation in cell membranes and preventing the formation of lipid hydroperoxides (Halliwell, 1987). If formed, potentially toxic lipid hydroperoxides are released from the cell membrane by phospholipase $A_{2}$ (EC 3.1.1.4) (van Kuijk et al. 1987) and degraded by selenium-dependent glutathione peroxidase $(E C 1.11 .1 .9)$. Hydrogen peroxide formed from $\mathrm{O}_{2}^{-}$by superoxide dismutase is prevented from forming $\mathrm{OH}^{*}$ by intervention of glutathione peroxidase and catalase $(E C 1 \cdot 11 \cdot 1 \cdot 6)$. $\beta$-Carotene has been recently suggested to have an antioxidant function (Willson, 1987). Vitamin $C$ in addition to directly scavenging free radicals in the cytoplasm may also participate in the regeneration of vitamin $\mathrm{E}$ and the antioxidant peptide, glutathione (Willson, 1987). In plasma, uric acid and proteins have pronounced antioxidant potential (Wayner et al. 1987) and peptides such as carnosine and homocarnosine (Kohen et al. 1988) may be important antioxidants in muscle tissue. A representation of the antioxidant defence mechanisms of the cell is shown in Fig. 1.

The effectiveness of the antioxidant defence system is dependent on adequate dietary intake of foods containing antioxidants such as vitamins $E$ and $C$ and the metal cofactors required for antioxidant enzymes. The antioxidant status of the body can be considerably 
influenced by diet (Slater et al. 1987), and should the normal defence mechanisms be weakened by nutritional deficiencies then pathognomonic consequences may occur. Recent evidence suggests that a relative deficiency in antioxidants in conjunction with relatively high concentrations of peroxidizable substrate may potentially have an important role to play in the development of the atheromatous plaque.

\section{EXPERIMENTAL EVIDENCE IMPLICATING FREE RADICALS IN ATHEROSCLEROSIS}

\section{LIPID HYDROPEROXIDES}

It is generally accepted that damage to the arterial endothelium is a prerequisite for subsequent development of the occlusive atheromatous plaque but the cause of the initial lesion is not known (Dodson \& Horton, 1987). Lipid hydroperoxides derived from free radical-mediated oxidation of polyunsaturated fatty acids are capable of causing such damage. Monolayers of porcine pulmonary artery endothelial cells are irreversibly damaged by linoleic acid hydroperoxides $(18: 2-\mathrm{OOH})$ as judged by enhanced albumin transfer across the monolayer (Hennig et al. 1986). Such damage is inhibited by previous incubation of the cells with vitamin E (Hennig et al. 1987). In addition, when serum lipid hydroperoxide levels of rabbits are elevated by injection of $18: 2-\mathrm{OOH}$ into the bloodstream, marked damage and denudation of aortic endothelial cells is observed (Yagi, 1987). Aggregation of platelets around the sites of injury was also observed. Platelets may participate in the early stages of the atheroma (Betteridge, 1987). As prostacyclin production, which normally impairs platelet aggregation and adherence, is inhibited by lipid hydroperoxides (Moncada et al. 1976) conditions appropriate for initiating atherogenesis may arise. It is possible that a relatively low antioxidant status could lead to raised serum lipid hydroperoxides. Formation of lesions and platelet adherence may then take place. Interestingly, serum lipid hydroperoxide concentrations in males increase with age, achieving a plateau between 41 and 50 years (Yagi, 1987). Women, who have a much lower incidence of CVD, do not have such a marked age-related increase in serum hydroperoxides (Yagi, 1987). High lipid hydroperoxide concentrations in serum are also found in diabetics, a high CVD risk group (Yagi, 1987). Although suggestive, such observations do not prove a causal relationship between lipid hydroperoxides and atheroma. Similarly, reported increases in lipid hydroperoxides in patients with diagnosed atherosclerosis (Miki quoted by Yagi, 1987) do not necessarily mean that lipid hydroperoxides have caused the disease. Such increases may have arisen as a secondary consequence of the disease state.

There is much interest in the prophylactic effect of polyunsaturated fatty acids on CVD (Bang, 1988), particularly in relation to $\omega$-3 fatty acids in fish oils. However, the relative ease of fatty acid peroxidation both by endogenous free radical activity and through oxidation in the gastrointestinal tract may be detrimental in subjects of marginal and low antioxidant status due to the formation of lipid hydroperoxides. Polyunsaturated fatty acids may be atherogenic (Diplock, 1987).

\section{OXIDATION OF LOW-DENSITY LIPOPROTEINS}

The appearance of lipid-laden foam cells at the site of injury in the blood vessel wall contributes to the growth of the atheromatous plaque. Such cells are derived from monocyte-macrophages and arterial smooth muscle cells (Mitchison \& Ball, 1987; Quinn et al. 1987). The processes involved in the formation of foam cells are not completely 
understood but uptake of oxidized low-density lipoproteins (LDL) is a major factor. LDL have been implicated in atherosclerosis for many years (Rudel et al. 1986). LDL, in addition to being a major carrier of cholesterol in the bloodstream (Brown \& Goldstein, 1986 ) is also a major carrier of vitamin E. Despite the presence of the antioxidant, LDL is susceptible to oxidation, presumably because it contains large amounts of unsaturated fatty acids (Heinecke, 1987). The content of vitamin $E$ is markedly decreased in oxidized LDL (Jurgens et al. 1987). Compared to native LDL, oxidized LDL exhibits a number of properties which are potentially atherogenic. These include recognition and preferential uptake by scavenger receptors of macrophages, chemotactic responses with respect to other monocytes-macrophages and regulation of a platelet-derived growth factor produced by endothelial cells (Jurgens et al. 1987). Monocytes may be attracted to the site of injury on the artery wall by mechanisms as yet unclear (Quinn et al. 1987). Uptake of oxidized LDL by monocytes promotes chemotactic attraction of monocytes-macrophages in vitro. However, on phenotypic transformation of monocytes to macrophages, oxidized LDL appears to inhibit macrophage motility, thus potentially reducing their ability to migrate away from the arterial wall. The enhanced rate of uptake of oxidized LDL may then convert macrophages into foam cells (Steinbrecher et al. 1984; Heinecke, 1987; Quinn et al. 1987; Hennig \& Chow, 1988). Because the macrophage itself can oxidatively modify native LDL, autocatalytic progression may lead to the continuous growth of the atheroma (Quinn et al. 1987). Lipid hydroperoxides also appear to enhance the incorporation of oxidized LDL into cultures of endothelial cells and macrophages (Hennig \& Chow, 1988), thus potentially contributing to plaque formation. In addition, oxidized LDL is capable of damaging endothelial cells directly, thus possibly further exacerbating growth of plaques (Heinecke, 1987).

The mechanisms by which LDL is oxidized are not precisely defined. Although LDL can be modified by lipoxygenases and phospholipase $A_{2}$ (Sparrow et al. 1988), major contenders for LDL oxidation in vivo are oxygen radicals. Sources of these oxygen radicals are likely to be macrophages and endothelial cells. Hiramatsu et al. (1987) showed that human monocytes stimulated to produce $\mathrm{O}_{2}^{-}$readily oxidized LDL. $\mathrm{O}_{2}^{-}$appeared to be the initiator of oxidation as the reaction was inhibited by the early addition of superoxide dismutase. However, once initiated, oxidation was $\mathrm{O}_{2}^{-}$independent, suggesting that other unknown factors were involved in the subsequent propagation process. Oxidation was also dependent on the presence of transition metals, implicating $\mathrm{OH}^{*}$ in the propagation process.

Cultures of endothelial and smooth muscle cells are also capable of oxidizing LDL by free radical-mediated mechanisms (Steinbrecher et al. 1984). LDL modification is directly proportional to the rate of $\mathrm{O}_{2}^{-}$production (Heinecke et al. 1986). The biochemical bases for $\mathrm{O}_{2}^{-}$production and LDL oxidation by endothelial and smooth muscle cells are unclear but appear to be dependent on the presence of L-cystine (Heinecke, 1987). Other possible sources of $\mathrm{O}_{2}^{-}$are through the activity of xanthine oxidase and the NADPH cytochrome P450 reductase-dependent reactions in microsomes (Hennig et al. 1987).

Whether or not oxidized LDL contributes to atherogenesis remains a matter of speculation. However, oxidized lipids have been detected in atherosclerotic plaques (Glavind et al. 1952), suggesting that some of the in vitro observations described previously may occur in vivo. The possibility that a low nutritional antioxidant status predisposes the individual to develop atherosclerosis due to enhanced oxidation of LDL requires further study. However, the scheme in Fig. 2 summarizes a potential mechanism for the development of the atheroma. 


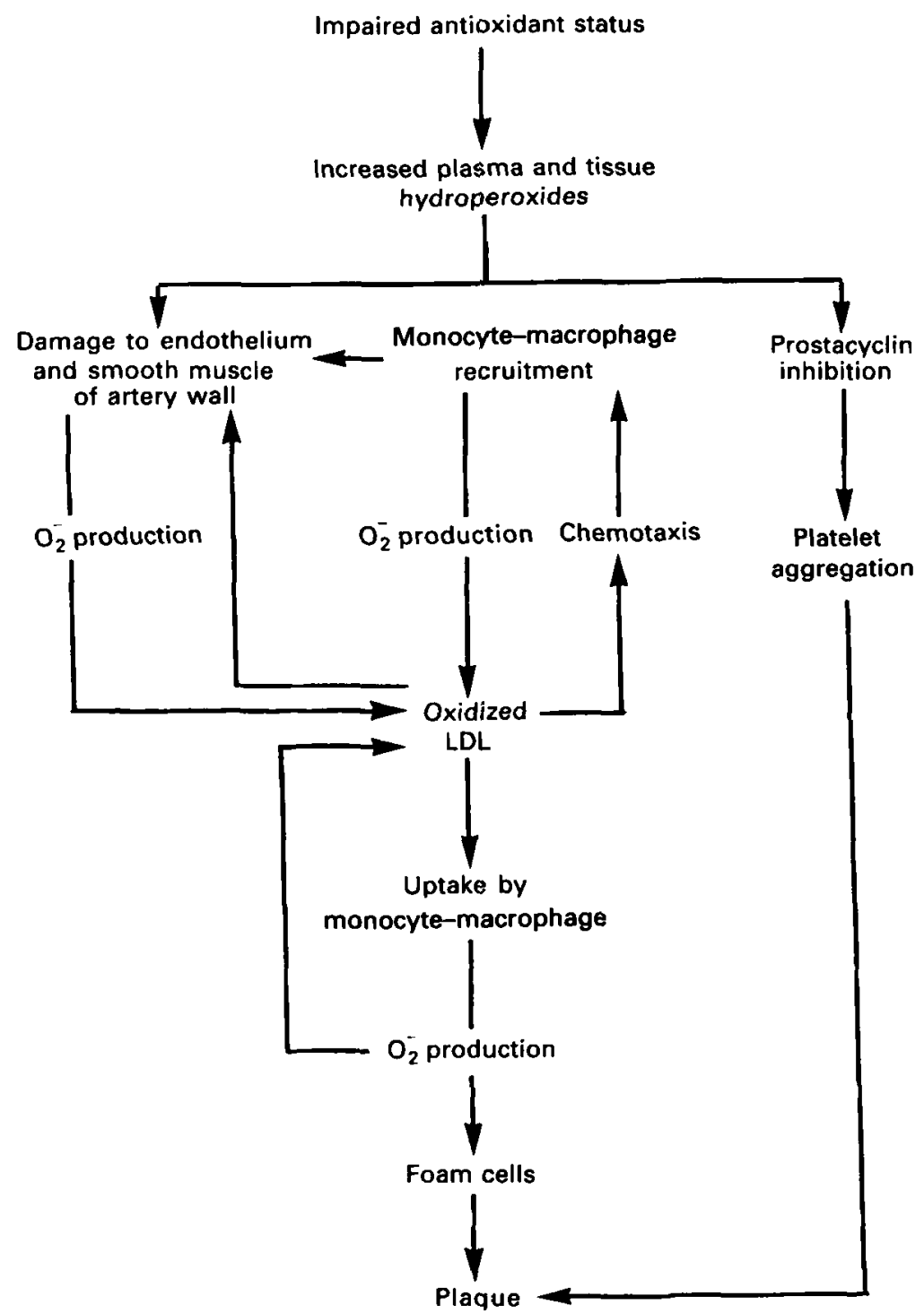

Fig. 2. Flow diagram of possible interactions contributing to the development of the atheromatous plaque. For detailed explanation see p. 55. LDL, low-density lipoprotein; $\mathrm{O}_{2}^{-}$, superoxide anion.

\section{EPIDEMIOLOGICAL EVIDENCE FOR FREE RADICAL INVOLVEMENT IN CARDIOVASCULAR DISEASE}

Epidemiological studies may not provide mechanisms for the development of disease but can indicate correlations which may be worthy of causal investigation. Interpretation of epidemiological results may also lead to contention. McCormick \& Strabanek (1988) point out that to date over 246 risk factors have been identified for CVD, many of which are presumably spurious. Bearing this in mind, recent epidemiological evidence suggests that 
inverse correlations between antioxidants and mortality from CVD do exist. Standardized mortality from CVD is statistically related to consumption of fruit and green vegetables from which vitamin C intake can be interpolated (Palgi, 1981; Acheson \& Williams, 1983) and to plasma vitamin C (Gey et al. 1987b). Gey (1986) and Gey et al. (1987a) in crosscultural investigations found that the cumulative 'antioxidant index',

cholesterol

vitamin $\mathrm{A} \times$ vitamin $\mathrm{E}$ (stand) $\times$ vitamin $\mathrm{C} \times \beta$-cartotene $\times \mathrm{Se}$,

derived from actual measurements of the nutrients in plasma was strongly and negatively correlated with age-standardized mortality for CVD. Recent provisional information involving the determination of antioxidants in plasma of middle-aged men from twelve European populations reveals significant correlations between age-specific mortality and lipid-standardized vitamin E and vitamin A ( $r^{2} 0.49$ and 0.33 respectively; Gey \& Puska, 1988). On the basis of such observations, Diplock (1987) has suggested that the recommended daily allowances for vitamin $\mathrm{E}$ and vitamin $\mathrm{C}$ should be increased 3-5-fold and 2-fold respectively. Intervention trials involving supplementation with antioxidant vitamins would appear to be warranted. However, it should be noted that cohort studies, which may be of greater value than correlational studies, have found no association between vitamin E and CVD (Salonen et al. 1985; Kok et al. 1987).

\section{ANTIOXIDANTS AND CARDIOVASCULAR DISEASE: INDIRECT EVIDENCE}

Evidence that mega-dose supplementation with antioxidants provides effective treatment for atherosclerosis is anecdotal, ill-controlled and lacking in scientific consistency (Walquist \& Flint, 1983; Diplock, 1987). However, some indicative experimental results are worth mentioning.

\section{VITAMIN E}

Wilson et al. (1978) found that addition of $10 \mathrm{~g}$ vitamin $\mathrm{E} / \mathrm{kg}$ to the diets caused a marked reduction in aortic and coronary atherosclerosis in rabbits. Similar effects were not apparent when diets were supplemented with antioxidants such as butylated hydroxytoluene suggesting that the effect of vitamin $E$ was not related to its function as an antioxidant.

Smokers, a CVD high-risk group in Northern latitudes, show a response to vitamin E supplements. Smokers' alveolar fluid is deficient in vitamin E (Pacht et al. 1986). A potential consequence of an impaired antioxidant content of the lungs is enhanced peroxidation of erythrocyte membranes in transit through the alveolar capillaries. Duthie et al. (1989) found that erythrocytes of smokers were more susceptible to hydrogen peroxide-induced peroxidation in vitro compared with those of non-smokers. This effect was abolished when smokers were supplemented with $1 \mathrm{~g}$ vitamin $\mathrm{E} / \mathrm{d}$ for 2 weeks. Similarly, the increased pentane expiration observed in smokers is reduced by vitamin $E$ supplements (Shariff et al. 1988). Plasma indices of lipid peroxidation are also increased in smokers (Duthie et al. 1989). Smokers appear to be particularly susceptible to free radical activity which may lead to oxidation of LDL and plaque development. Further, although a strong correlation exists between number of cigarettes smoked and incidence of CVD in Northern Europe, such a relationship is less marked in Southern Europe and Japan (Waterlow, 1988). This may reflect differences in consumption of food containing antioxidants such as vitamin $E$. 


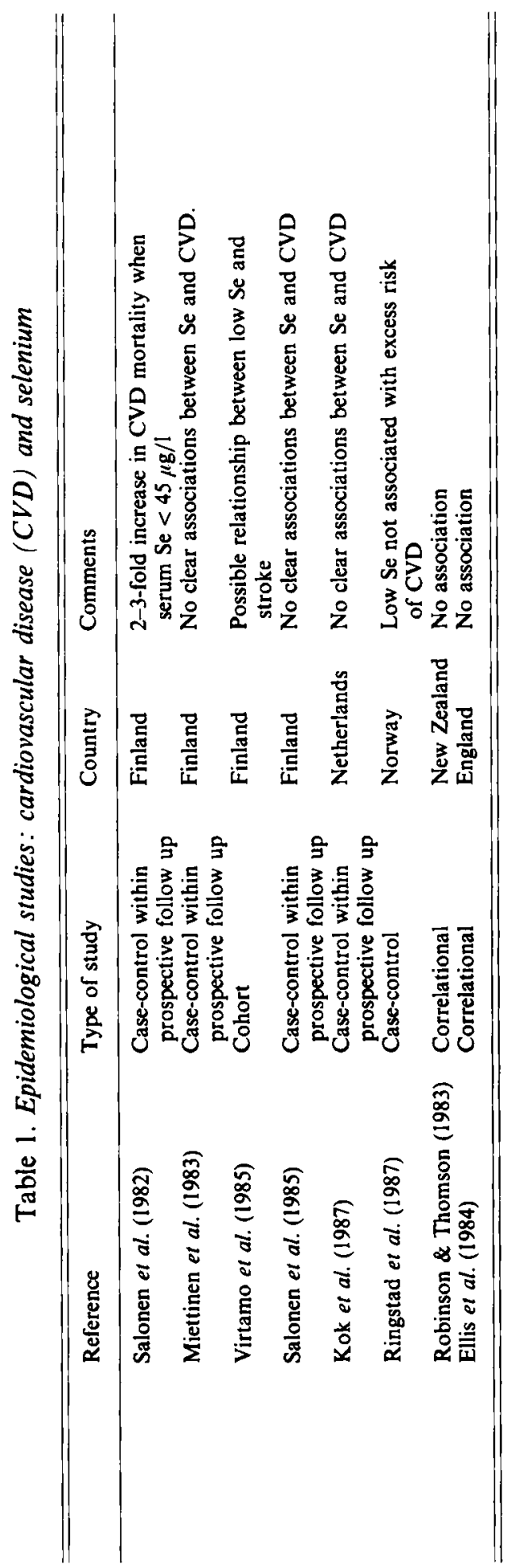




\section{VITAMIN C}

Cigarette smokers have lower plasma vitamin C concentrations (Pelletier, 1968; Duthie et al. 1989) and possibly abnormal ascorbate turnover (Kallner et al. 1981) than nonsmokers. However, vitamin $C$ has many biochemical functions (Levine, 1986). Whether or not the lower ascorbate concentrations in smokers reflect increased oxidant stress is not certain. In guinea-pigs, marginal vitamin $\mathrm{C}$ deficiency is associated with the appearance of intimal plaques (Sulkin \& Sulkin, 1975). Further, leucocyte ascorbic acid is significantly lower in patients with atherosclerosis compared with controls (Ramirez \& Flowers, 1980). Vitamin C concentrations are also low in aortic tissue from patients with atherosclerotic occlusive disease (Dubick et al. 1987). Such observations, although indicative, do not directly implicate vitamin C as an aetiological factor in CVD, nor do they necessarily invoke its function as a biological antioxidant.

\section{SELENIUM}

Although not in itself an antioxidant, Se is the essential metal cofactor for the activity of the antioxidant enzyme, glutathione peroxidase (Rotruck et al. 1973). Therefore, a low Se status could theoretically lead to increased intimal damage by lipid hydroperoxides and increased susceptibility of LDL to oxidation. In addition, Se deficiency may also lead to impaired prostacyclin synthesis (Schoene et al. 1986), thus promoting platelet aggregation. However, findings from studies relating blood Se levels to CVD are equivocal (Ringstad, 1988). For example, Salonen et al. (1982) found an inverse association between serum Se and risk of death from CVD, whereas no such association was observed by Miettinen et al. (1983) and Kok et al. (1987). In addition, no differences in tissue Se were apparent in patients who died with, or without, myocardial infarction (Ringdal et al. 1986). References of studies relating Se and CVD are given in Table 1. Low Se does not appear to be an independent risk factor in countries with intermediate Se intake. Moreover, the Finnish findings suggest that, even for low Se areas, the available evidence is inconsistent. Consequently, although Se deficiency has long been known to cause cardiomyopathies in animals (Burk, 1978) and is associated with Keshan disease in humans (Yang et al. 1984), evidence for its involvement in CVD is minimal. In addition, whereas vitamin $\mathrm{E}$ is well tolerated in large doses (Bendich \& Machlin, 1988), Se is potentially toxic and therapeutic supplementation with Se as a preventative measure is not warranted (Diplock, 1987).

\section{$\beta$-CAROTENE}

Also known as provitamin $A, \beta$-carotene has antioxidant capability. In vitro, small amounts retard oxidation of methyl linoleate. It is particularly effective at low partial pressures of $\mathrm{O}_{2}$ at which its antioxidant capacity exceeds that of vitamin $\mathrm{E}$ (Burton, 1989).

Consequently, $\beta$-carotene could assume importance during the ischaemia and reperfusion events that occur during a heart attack. In addition, $\beta$-carotene scavenges superoxide in cell cultures (Krinsky, 1989). As the provitamin is transported in plasma mainly in the LDL (Parker, 1989), potentially it could play a protective role in limiting LDL oxidation. As yet there is little evidence available to assess whether increasing the dietary intake of $\beta$-carotene by supplementation or by increasing consumption of fruit and vegetables reduces the risk of CVD. However, observations that serum concentrations of $\beta$-carotene are greater in women than in men (Parker, 1989) and that the carotenoid intakes of male smokers are only $70-80 \%$ those of non-smokers (Ziegler, 1989) suggest that further study of the relationship between carotenoids and CVD is worthwhile. 


\section{CONCLUSION}

The field of research into CVD is immense, risk factors abound and controversy continues unabated as to the causes of the disease. Therefore, it is with some trepidation that we suggest that free radicals are implicated in the pathogenesis of CVD. Nevertheless, the recent experimental evidence relating to $\mathrm{LDL}$ oxidation and the epidemiological correlations between plasma antioxidant concentrations and incidence of CVD indicate that biochemical reactions involving oxidant stress may provide a much needed mechanistic basis for the disease. The possibility that nutritional intervention to increase intake of antioxidants may reduce mortality from CVD requires investigation.

\section{REFERENCES}

Acheson, R. M. \& Williams, D. D. R. (1983). Does consumption of fruit and vegetables protect against stroke? Lancel i, 1191-1193.

Bang. H. O. (1988). N-3 fatty acids in the diet or as a food supplement. International Clinical Nutrition Review 8 , 21-28.

Bast, A. (1986). Is formation of reactive oxygen by cytochrome P-450 perilous and predictable? Trends in Pharmacological Science 7, 266-270.

Bendich, A. \& Machlin. L. J. (1988). Safety of oral intake of vitamin E. American Journal of Clinical Nutrition 48 , 612.619.

Betteridge, J. (1987). Nutrition and platelet function in atherogenesis. Proceedings of the Nutrition Society 46. 345-359.

Brown, M. S. \& Goldstein, J. L. (1986). A receptor mediated pathway for cholesterol homeostasis. Science 232 , 34-47.

Burk, R. F. (1978). Selenium in nutrition. World Review of Nutrition and Dietetics 30, 88-106.

Burton, G. W. (1989). Antioxidant action of carotenoids. Journal of Nutrition 119, $109-111$.

Byczkowski, J. Z. \& Gessner, T. (1988). Biological role of superoxide ion-radical. International Journal of Biochemistry' 20, 569-580.

Church, D. F. \& Pryor, W. A. (1985). Free-radical chemistry of cigarette smoke and its toxicological implications. Environmental Health Perspectives 64, 111-126.

Diplock, A. T. (1987). Dietary supplementation with antioxidants. Is there a case for exceeding the recommended dietary allowance? Free Radicals in Biology and Medicine 3, 199-201.

Dodson, P. M. \& Horton, R. C. (1987). The nature of the atheroma. Proceedings of the Nutrition Society 46 , 331-336.

Dubick, M. A.. Hunter, G. C., Casey, S. M. \& Keen, C. L. (1987). Aortic ascorbic acid, trace elements, and superoxide dismutase activity in human aneurysmal and occlusive disease. Proceedings of the Society for Experimental Biology' and Medicine 184, 138-143.

Duthie, G. G., Arthur, J. R., James, W. P. T. \& Vint, H. M. (1989). Antioxidant status of smokers and nonsmokers: effects of vitamin E supplementation. Annals of the New York Academy of Sciences (In the Press).

Duthie, G. G., Arthur, J. R. \& Mills, C. F. (1987). Tissue damage in vitamin E deficient rats is not detected by expired ethane and pentane. Free Radical Research Communications 4, 21-25.

Ellis, N., Lloyd, B., Lloyd, R. S. \& Clayton, B. E. (1984). Selenium and vitamin E in relation to risk factors for coronary heart disease. Journal of Clinical Pathology 37, 200-206.

Forman, H. J. \& Boveris, A. (1982). Superoxide radical and hydrogen peroxide in mitochondria. In Free Radicals in Biology, vol. 5. pp. 65-90 [W. A. Pryor, editor]. New York: Academic Press.

Fridovich, I. (1983). Superoxide radical: an endogenous toxicant. Annual Review of Pharmacology and Toxicology 23, 239-257.

Gey, K. F. (1986). On the antioxidant hypothesis with regard to arteriosclerosis. Bibliotheca Nutritio et Dieta 37, 5391.

Gey, K. F., Brubacher, G. B. \& Stähelin, H. B. (1987a). Plasma levels of antioxidant vitamins in relation to ischaemic heart disease and cancer. American Journal of Clinical Nutrition 45, 1368-1377.

Gey, K. F. \& Puska, P. (1988). Plasma vitamins E and A inversely correlated to ischemic heart disease (IHD) mortality in cross-sectional epidemiology. Annals of the New York Academy of Sciences Abstr. (In the Press).

Gey, K. F., Stähelin, H. B., Puska, P. \& Evans. A. (1987b). Relationship of plasma level of vitamin C to mortality from ischemic heart disease. Annals of the New York Academy of Sciences 498, 110-123.

Glavind, J., Hartmann, S., Clemmesen, J., Jessen, K. E. \& Dam, H. (1952). Role of lipoperoxidases in human pathology. Il. The presence of peroxidized lipids in the atherosclerotic aorta. Acta Pathologica et Microbiologica Scandinavica 30, 1-6. 
Grundy, S. M. (1986). Cholesterol and coronary heart disease. A new era. Journal of the American Medical Association 256, 2849-2858.

Halliwell, B. (1987). Oxidants in human disease: some new concepts. FASEB Journal 1, 358-364.

Halliwell, B. \& Grootveld, M. (1987). The measurement of free radical reactions in humans. Some thoughts for future experimentation. FEBS Letlers 213, 9-14.

Halliwell, B. \& Gutteridge, M. C. (1985). Free Radicals in Biology and Medicine. Oxford: Clarendon Press.

Heinecke, J. W. (1987). Free radical modification of low-density lipoprotein: mechanisms and biological consequences. Free Radicals in Biology and Medicine 3, 65-73.

Heinecke, J. W., Baker, L., Rosen, H. \& Chait, A. (1986). Superoxide mediated modification of low density lipoprotein by arterial smooth muscle cells. Journal of Clinical Investigation 77, 757-761.

Hennig, B. \& Chow, C. K. (1988). Lipid peroxidation and endothelial cell injury: implications in atherosclerosis. Free Radicals in Biology and Medicine 4, 99-106.

Hennig, B., Enoch, C. \& Chow, C. K. (1986). Linoleic acid hydroperoxide increases the transfer of albumin across cultured endothelial monolayers. Archives of Biochemistry and Biophysics 248, 353-357.

Hennig, B., Enoch, C. \& Chow, C. K. (1987). Protection by vitamin E against endothelial cell injury by linoleic acid hydroperoxides. Nutrition Research 7, 1253-1259.

Hiramatsu, K., Rosen, H., Heinecke, J. W., Wolfbaver, G. \& Chait, A. (1987). Superoxide initiates oxidation of low density lipoprotein by human monocytes. Arteriosclerosis 7, 55--60.

Iversen, S. A., Cawood, P. \& Dormandy, T. L. (1985). A method for the measurement of a diene-conjugated derivative of linoleic acid, 18:2 $(9,11)$, in serum phospholipid, and possible origins. Annals of Clinical Biochemistry 22, 137-140.

James, W. P. T. \& Ralph, A. (1988). Should the national diet be altered to prevent coronary disease? Proceedings of the Nutrition Society 47, 3-8.

Jurgens, G., Hoff, H. F., Chisholm, G. M. \& Esterbauer, H. (1987). Modification of human serum low density lipoprotein by oxidation - characterization and pathophysiological implications. Chemistry and Physics of Lipids 45, 315-336.

Kallner, A. B., Hartman, D. \& Hornig. D. H. (1981). On the requirements of ascorbic acid in man: steady state turnover and body pool in smokers. The American Journal of Clinical Nutrition 34, 1347-1355.

Klebanoff, S. J. (1982). Oxygen-dependent cytotoxic mechanisms of phenocytes. In Advances in Host Defense Mechanisms, vol. 1, pp. 111-162 [J. I. Gallin and A. S. Fauci, editors]. New York: Raven Press.

Kohen, R., Yamamoto, Y., Lundy, K. C. \& Ames, B. N. (1988). Antioxidant activity of carnosine, homocarnosinẹ. and anserine present in muscle and brain. Proceedings of the National Academy of Sciences of the USA 85 . 3175-3179

Kok, F. J., de Bruijn, A. M., Vermeeren, R., Hofman, A., Van Laar, A., de Bruin, M., Hermus, R. J. J. \& Valkenburg, H. A. (1987). Serum selenium, vitamin antioxidants, and cardiovascular mortality: a 9-year follow-up study in the Netherlands. American Journal of Clinical Nutrition 45, 462-468.

Koster, J. F. \& Slee, R. G. (1986). Ferritin, a physiological iron donor for microsomal lipid peroxidation. FEBS Lellers 199, 85-88.

Krinsky, N. l. (1989). Carotenoids and cancer in animal models. Journal of Nutrition 119, 123 126.

Levine, M. (1986). New concepts in the biology and biochemistry of ascorbic acid. New England Journal of Medicine 314, 892-902.

McCormick. J. \& Skrabanek, P. (1988). Coronary heart disease is not preventable by population interventions. Lancer ii, 839-841.

Miettinen, T. A., Alfthan, G., Huttunen, J. K., Pikkarainen, J., Naukkarimen, V., Mattila, S. \& Kumlin, T. (1983). Serum selenium concentration related to myocardial infarction and fatty acid content of serum lipids. British Medical Journal 287, 517-519.

Mitchison, M. J. \& Ball, R. Y. (1987). Macrophages and atherogenesis. Lancet ii, 146-148.

Moncada, S., Gryglewski, S., Bunting, S. \& Vane, J. R. (1976). An enzyme isolated from arteries transforms prostaglandin endoperoxides to an unstable substance that inhibits platelet aggregation. Nature 263, 663.665 .

Pacht, E. R., Kaseki, H., Mohammed, J. R., Cornwell, D. G. \& Davis, W. B. (1986). Deficiency of vitamin E in the alveolar fluid of cigarette smokers. Journal of Clinical Investigation 77, 789-796.

Palgi, A. (1981). Association between dietary changes and mortality rates: Israel 1949 to 1977; a trend-free regression model. American Journal of Clinical Nutrition 34, I 569-1583.

Parker, R. S. (1989). Carotenoids in human blood and tissues. Journal of Nutrition 119, $101-104$.

Pelletier, O. (1968). Smoking and vitamin C levels in humans. American Journal of Clinical Nutrition 21. 1259-1267.

Quinn, M. T., Parthasarathy, S., Fong, L. G. \& Steinberg, D. (1987). Oxidatively modified low density lipoproteins: a potential role in recruitment and retention of monocyte/macrophages during atherogenesis. Proceedings of the National Academy of Sciences of the USA 84, 2995-2998.

Ramirez, J. \& Flowers, N. C. (1980). Leukocyte ascorbic acid and its relationship to coronary artery disease in man. American Journal of Clinical Nutrition 33, 2079-2087.

Reckless, J. P. D. (1987). Can nutrition favourably affect serum lipids? Proceedings of the Nutrition Society 46 , $36[-366$. 
Rifkind, B. M. (1987). Diet, cholesterol and coronary heart disease: the Lipid Research Clinics Programme. Proceedings of the Nutrition Society 46, 367-372.

Ringdal, O., Anderson, K. J., Svendsen, E. \& Julsham, K. (1986). Trace elements and myocardial infarction, and autopsy study from Western Norway. Acta Pharmacologica el Toxicologica 59, Suppl. 7, 358-360.

Ringstad, J. (1988). Selenium in cardiovascular disease and cancer. Epidemiological and experimental studies. PhD Thesis, University of Tromsø.

Ringstad. J., Jacobsen, B. K., Thomassen, Y. \& Thelle, D. S. (1987). The Tromse heart study: serum selenium and risk of myocardial infarction, a nested case-control study. Journal of Epidemiology and Community Health 41, 329-332.

Robinson. M. F. \& Thomson, C. D. (1983). The role of selenium in the diet. Nutrition Abstracts and Reviews 53, 3-26.

Ross, R. (1986). The pathogenesis of atherosclerosis - an update. New England Journal of Medicine 314, 488-500.

Rotruck, J. T., Pope, A. L., Ganther, H. E., Swanson, A. B., Hafeman D. G. \& Hoekstra, W. G. (1973). Selenium: Biochemical role as a component of glutathione peroxidase. Science 179, 588-590.

Rudel, L. L., Parks, J. S., Johnson, F. L. \& Babiak, J. (1986). Low density lipoproteins in atherosclerosis. Journal of Lipid Research 27. 465-474.

Salonen. J. T., Alfthan, G., Pikkarainen, J., Huttunen, J. K. \& Puska, P. (1982). Association between cardiovascular death and myocardial infarction and serum selenium in a matched-pair longitudinal study. Lancet ii, 175-179.

Salonen, J. T., Salonen, R., Pentilla, I., Herranen, J., Jauhiainen, M., Kantola, M., Lappeteläinen, R., Mäenpää, P. H., Alfthan, G. \& Puska, P. (1985). Serum fatty acids, apolipoproteins, selenium and vitamin antioxidants and the risk of death from coronary heart disease. American Journal of Cardiology 56, 226-231.

Schoene, N. W., Morris, V. C. \& Levander, O. A. (1986). Altered arachidonic acid metabolism in platelets and aortas from selenium-deficient rats. Nutrition Research 6, 75-83.

Shariff, R., Hoshino, E., Allard, J., Pichard, C., Kurian, R. \& Jeejeebhoy, K. N. (1988). Vitamin E supplementation in smokers. American Journal of Clinical Nutrition 47, 758.

Slater, T. F. (1984). Free radical mechanisms in tissue injury. Biochemical Journal 222, 1-15.

Slater, T. F., Cheeseman, K. H., Davies, M. J., Proudfoot, K. \& Xin, W. (1987). Free radical mechanisms in relation to tissue injury. Proceedings of the Nutrition Society 46, 1-12.

Slattery, M. L. \& Randall, D. E. (1988). Trends in coronary heart disease mortality and food consumption in the United States between 1909 and 1980. American Journal of Clinical Nutrition 47, 1060-1067.

Sparrow, C. P., Parthasarathy, S. \& Steinberg, D. (1988). Enzymatic modification of low density lipoprotein by purified lipoxygenase plus phospholipase $\mathrm{A}_{2}$ mimics cell-mediated oxidative modification. Journal of Lipid Research 29, 745-753.

Steinbrecher, V. P., Parthasarathy, S., Leake, D. S., Witztum, J. L. \& Steinberg, D. (1984). Modification of low density lipoprotein by endothelial cells involves lipid peroxidation and degradation of low density lipoprotein phospholipids. Proceedings of the National Academy of Sciences of the USA 81, 3883-3887.

Sulkin, N. M. \& Sulkin, D. F. (1975). Tissue changes induced by marginal vitamin C deficiency. Annals of the New York Academy of Sciences 258, 317-322.

Tyroler, H. A. (1987). Review of lipid-lowering clinical trials in relation to observational epidemiologic studies. Circulation 76, 515-522.

van Kuijk, F. J. G. M., Sevanian, A., Handelman, G. J. \& Dratz, E. A. (1987). A new role for phospholipase $A_{2}$ : protection of membranes from lipid peroxidation damage. Trends in Biological Science 12, 31-34.

Virtamo, J., Valkeila, E., Alfthan, G., Punsar, S., Huttunen, J. K. \& Karvonen, M. J. (1985). Serum selenium and the risk of coronary heart disease and stroke. American Journal of Epidemiology 122, 276-282.

Wade, C. R. \& van Rij, A. M. (1988). Plasma thiobarbituric acid reactivity: reaction conditions and the role of iron, antioxidants and lipid peroxy radicals on the quantitation of plasma lipid peroxides. Life Sciences $\mathbf{4 3}$, $1085-1093$

Walquist, M. L. \& Flint, D. M. (1983). Megavitamin therapy: What is the evidence? Patient Management 12, 103-123.

Waterflow. J. C. (1988). General discussion. Diet and coronary disease. Proceedings of the Nutrition Society 47, $11-19$.

Wayner, D. D. M., Burton, G. W., Ingold, K. U., Barclay, L. R. C. \& Locke, S. J. (1987). The relative contributions of vitamin $\mathrm{E}$, urate, ascorbate and proteins to the total peroxyl radical-trapping antioxidant activity of human blood plasma. Biochimica et Biophysica Acta 924, 408-419.

Willson, R. L. (1987). Vitamin E, selenium, zinc and copper interactions in free radical protection against illplaced iron. Proceedings of the Nutrition Society 46, 27-34.

Wilson, R. B., Middleton, C. C. \& Sun, G. Y. (1978). Vitamin E, antioxidants and lipid peroxidation in experimental atherosclerosis of rabbits. Journal of Nutrition 108, $1858-1867$.

Yagi, K. (1987). Lipid peroxides and human diseases. Chemistry and Physics of Lipids 45, 337-351.

Yang, G., Chen, J., Wen, Z., Ge, K., Zhu, L., Chen, X. \& Chen, X. (1984). The role of selenium in Keshan Disease. Advances in Nutrition Research 6, 203-231.

Ziegler, R. G. (1989). A review of epidemiologic evidence that carotenoids reduce the risk of cancer. Journal of Nutrition 119. 116-122. 